\title{
Preparation of Ag-Sm Co-doped TiO2 Catalyst by Microwave Hydrothermal Method and Its Photocatalytic Activity
}

\author{
Cheng chen ${ }^{1, a}$,Yuejie $\mathrm{Lu}^{1, \mathrm{~b}}$ and Xianjun $\mathrm{Bi}^{1, \mathrm{c} *}$ \\ ${ }^{1}$ Institute of Chemistry and Chemical Engineering Yunnan Normal University, Yunnan Kunming, \\ China \\ a star470013181@126.com, ${ }^{\text {b } 1079260276 @ q q . c o m, ~}{ }^{c}$ bixj159@qq.com \\ * The Corresponding Author
}

Keywords: Microwave hydrothermal method; Silver doped $\mathrm{TiO}_{2}$; Samarium doped $\mathrm{TiO}_{2}$; Silver-samarium co-doped $\mathrm{TiO}_{2}$; Photocatalytic activity

\begin{abstract}
The optimum conditions for the preparation of $\mathrm{TiO}_{2}-\mathrm{Ag}-\mathrm{Sm}$ photocatalysts by microwave hydrothermal method are as follows: $\mathrm{n}\left(\mathrm{Ag}^{+}\right): \mathrm{n}\left(\mathrm{Ti}^{4+}\right)=0.3 \%$, microwave power $600 \mathrm{~W}$, reaction temperature $150{ }^{\circ} \mathrm{C}$, reaction time $3 \mathrm{~h}$, calcination temperature $650{ }^{\circ} \mathrm{C}$ and calcination time $3 \mathrm{~h}$. The structure of the catalyst was characterized by XRD, SEM-EDS, ICP-AES, UV-Vis, IR and BET. The photocatalytic degradation activity of $\mathrm{TiO}_{2}-\mathrm{Ag}-\mathrm{Sm}$ catalyst was investigated under the conditions of microwave, ultraviolet, microwave-ultraviolet and microwave-ultrasonic-ultraviolet under methyl orange solution as simulated pollutant. The results showed that methyl orange was almost degraded completely when the methyl-orange solution was degraded by microwave-ultrasonic-ultraviolet irradiation for $25 \mathrm{~min}$.
\end{abstract}

\section{Introduction}

Compared with other semiconductor photocatalysts $\mathrm{CdS}, \mathrm{ZnO}, \mathrm{ZnS}$ and so on, $\mathrm{TiO}_{2}$ photocatalyst possesses high oxidation potential, stable chemical property, no secondary pollution and low price, so $\mathrm{TiO}_{2}$ photocatalyst has been extensively studied[1,2]. However, $\mathrm{TiO}_{2}$ has some defects in photocatalysis. Its forbidden band is wide $(\mathrm{Eg}=3.2 \mathrm{eV})$, and it can only be stimulated by ultraviolet. However, most of the sunlight is composed of visible light and ultraviolet light only 3-5\%, so its utilization of solar light is low, resulting in its low photocatalytic activity. In addition, the use of time-resolved spectroscopy found that most photoionization-hole $\left(\mathrm{e}^{-} / \mathrm{h}^{+}\right)$pairs in $\mathrm{TiO}_{2}$ have a high rate of anaplastic recombination after excitation, which is also a reason for the low efficiency of most semiconductor-based photocatalytic reactions[3,4].In view of $\mathrm{TiO}_{2}$ photocatalytic defects, it needs to be modified. Numerous studies have shown that doping metal ions can extend the photocatalytically active region of $\mathrm{TiO}_{2}$ to the visible region while doping can inhibit recombination of photogenerated electron-hole $\left(\mathrm{e}^{-} / \mathrm{h}^{+}\right)$pairs and promote the transfer of photogenerated electrons, thereby increasing photocatalytic activity of $\mathrm{TiO}_{2}[5-7]$.

Using microwave heating method combined with hydrothermal synthesis method can be prepared in a short time with small size and high purity uniform particles. The microwave can heat the solution in a short time, which can largely eliminate the influence of the temperature gradient on the synthesis. In the meantime, it is possible to crystallize the $\mathrm{TiO}_{2}$ colloidal particles rapidly during the preparation of the catalyst to obtain the ultrafine $\mathrm{TiO}_{2}$ particles[8-10]. In this paper, silver-samarium co-doped $\mathrm{TiO}_{2}$ photocatalyst was prepared by microwave hydrothermal method. The photocatalytic activity of the prepared catalyst was investigated with methyl orange solution as a simulated pollutant to further improve the photocatalytic activity of the doped $\mathrm{TiO}_{2}$ catalyst.

\section{Experimental Part}

The Main Reagent. Tetra-n-butyl titanate (AR, Sinopharm Chemical Reagent Co., Ltd.); silver nitrate (AR, Aladdin reagent); samarium nitrate (AR, Aladdin reagent); absolute ethanol (CP, Shanghai Chemical Reagent Factory); methyl orange (AR, Sinopharm Chemical Reagent Co., Ltd.); 
ultrapure water.

Preparation of $\mathrm{TiO}_{2}-\mathbf{A g}-\mathrm{Sm}$ catalyst and Photocatalytic Activity Test. Respectively, a certain amount of anhydrous ethanol and tetra-n-butyl titanate were mixed, the mixture was stirred magnetically for a certain time to get A solution; Weigh a certain amount of silver nitrate and samarium nitrate dissolved in dilute nitric acid and added dropwise to A solution stirred for a certain time to get B solution; The solution B was placed in a microwave hydrothermal parallel synthesizer (microwave power $600 \mathrm{~W}$, the reaction temperature $150{ }^{\circ} \mathrm{C}$, the reaction time $3 \mathrm{~h}$ ) to obtain a $\mathrm{TiO}_{2}$ sol, filtered, vacuum dried, milled, placed in a muffle furnace temperature calcined $3 \mathrm{~h}$ get $\mathrm{TiO}_{2}-\mathrm{Ag}-\mathrm{Sm}$ photocatalyst, bottling spare. The photocatalytic activity of the catalyst test methods are described in the literature[11,12].

Catalyst structure testing and characterization. The catalyst was scanned by X-ray diffractometer (XRD) to get the crystal form and grain size of the catalyst by data processing. The surface morphology of the catalyst was observed by scanning electron microscope (SEM), and the EDS was selected by specific microscopic region. To explore the elemental content in the catalyst, ICP-AES analysis of the utilization of the preparation of the catalyst in the process of chemical and elemental loading; UV-Vis spectrophotometer was used to measure its UV-Vis spectrum in the wavelength range of $200-800 \mathrm{~nm}$. The specific surface area analyzer was used to analyze the catalyst surface area, pore volume and pore size. The infrared spectrometer was used to measure the catalyst in the range of $4000-400 \mathrm{~cm}^{-1}$ Infrared spectrum.

\section{Results and Discussion}

Silver and Samarium Co-doped Amount of $\mathrm{TiO}_{2}$-Ag-Sm Photocatalytic Activity. Fixed other preparation conditions were unchanged, respectively, change the amount of silver or samarium doping in order to investigate the amount of silver or samarium doped $\mathrm{TiO}_{2}-\mathrm{Ag}-\mathrm{Sm}$ prepared by microwave hydrothermal photocatalytic activity, the results shown in Fig. 1 and Fig. 2.

The doping amount of element in the $\mathrm{TiO}_{2}$ catalyst can make it become the center of separation, and then reduce the photogenerated electron-hole recombination rate. As can be seen from Fig. 1 and Fig. 2, when the values of $n\left(\mathrm{Ag}^{+}\right): n\left(\mathrm{Ti}^{4+}\right)$ and $\mathrm{n}\left(\mathrm{Sm}^{3+}\right): \mathrm{n}\left(\mathrm{Ti}^{4+}\right)$ are $0.3 \%$, the degradation rate of methyl orange reaches $99.84 \%$ When the catalyst has a high photocatalytic activity, the optimal doping amount of $\mathrm{Sm}$ and $\mathrm{Ag}$ is $0.3 \%$, when the microwave hydrothermal method is used to prepare the $\mathrm{TiO}_{2}-\mathrm{Ag}-\mathrm{Sm}$ catalyst.

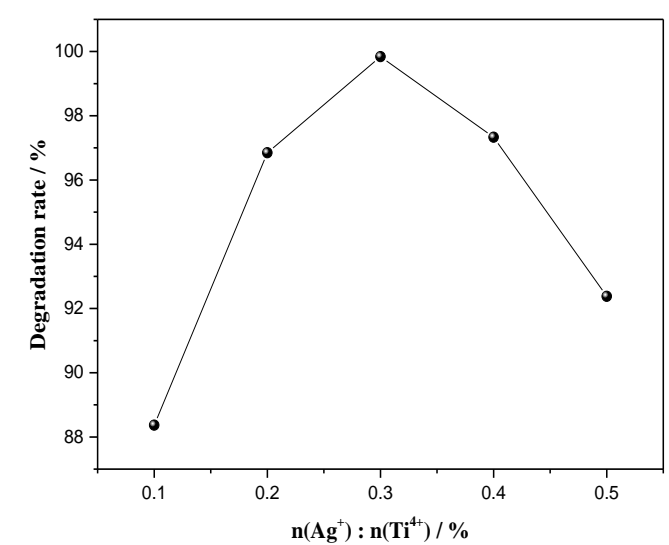

Figure 1. Finite The influence of $\mathrm{n}\left(\mathrm{Ag}^{+}\right) / \mathrm{n}\left(\mathrm{Ti}^{4+}\right)$ mole ratio on photocatalytic activity of $\mathrm{TiO}_{2}-\mathrm{Ag}-\mathrm{Sm}$

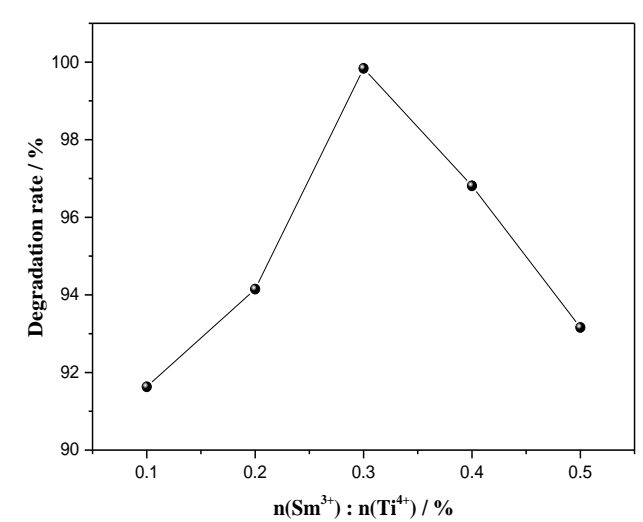

Figure 2. Finite The influence of $\mathrm{n}\left(\mathrm{Sm}^{3+}\right) / \mathrm{n}\left(\mathrm{Ti}^{4+}\right)$ mole ratio on photocatalytic activity of $\mathrm{TiO}_{2}-\mathrm{Ag}-\mathrm{Sm}$ 
Fig. 3 shows the XRD patterns of $\mathrm{TiO}_{2}-\mathrm{Ag}-\mathrm{Sm}$ and pure $\mathrm{TiO}_{2}$ prepared under the optimal conditions. By combining jade5 software phase retrieval analysis shows: pure $\mathrm{TiO}_{2}$ catalyst and anatase and rutile characteristics of the peak, which shows pure $\mathrm{TiO}_{2}$ from anatase and rutile two structures; calculated by RIR method two-phase formula can be two-phase, and the mass percentages are $32.95 \%$ and $67.05 \%$ respectively. The match between $\mathrm{TiO}_{2}-\mathrm{Ag}$-Sm catalyst and anatase is very high, and no other peaks appear in the spectrum, indicating that the $\mathrm{TiO}_{2}-\mathrm{Ag}-\mathrm{Sm}$ catalyst has a single crystal form. The size of the catalyst is calculated as follows: $\mathrm{TiO}_{2}(28.27 \mathrm{~nm})>$

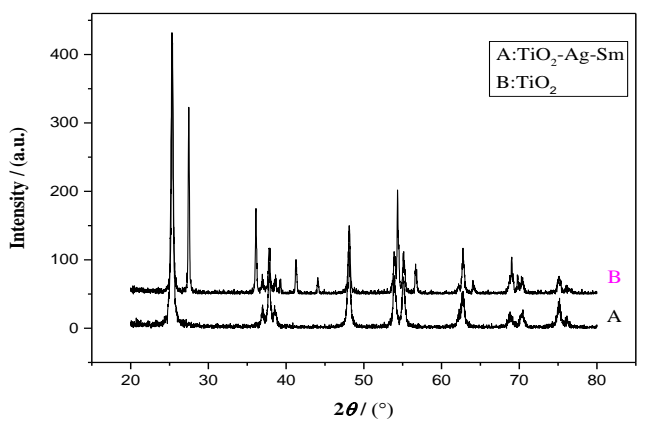

Figure 3. Finite XRD spectra of $\mathrm{TiO}_{2}-\mathrm{Ag}-\mathrm{Sm}$ and $\mathrm{TiO}_{2}$ photocatalyst( $\left.\mathrm{A}: \mathrm{TiO}_{2}-\mathrm{Ag}-\mathrm{Sm} \mathrm{B}: \mathrm{TiO}_{2}\right)$

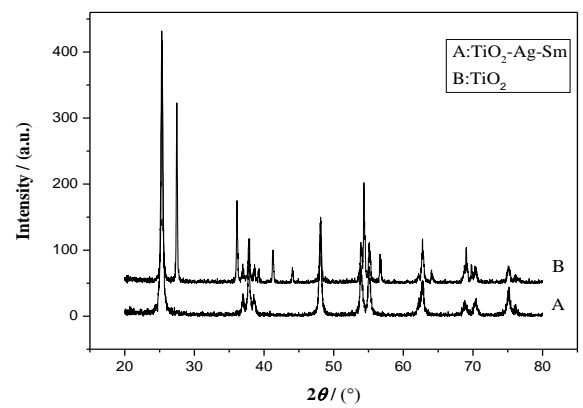

Figure 5. Finite $\mathrm{TiO}_{2}-\mathrm{Ag}-\mathrm{Sm}$ and pure $\mathrm{TiO}_{2}$ catalyst XRD patterns

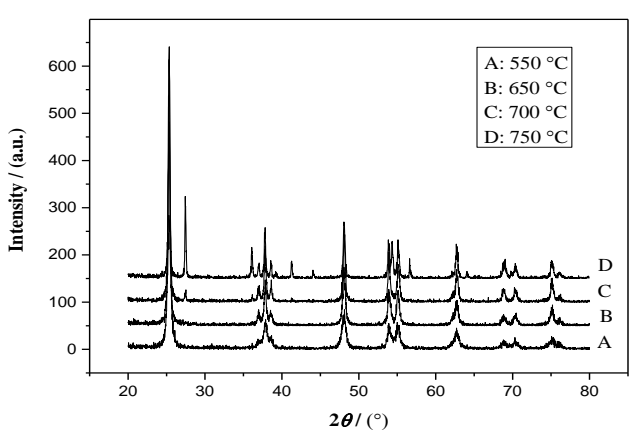

Figure 4. Finite Photocatalytic activity of $\mathrm{TiO}_{2}$-Ag-Sm catalyst under different degradation conditions

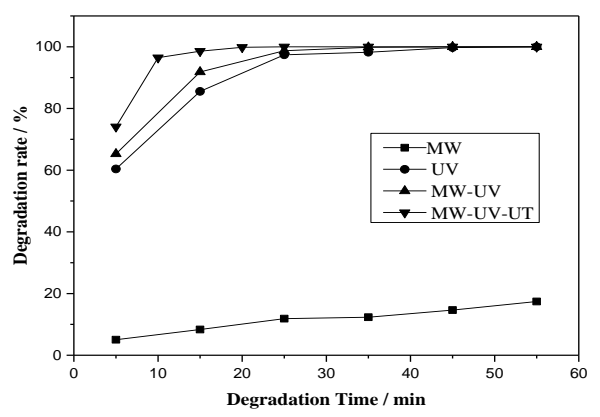

Figure 6. Finite XRD pattern of $\mathrm{TiO}_{2}-\mathrm{Ag}-\mathrm{Sm}$ catalyst calcined at different temperatures

$\mathrm{TiO}_{2}-\mathrm{Ag}-\mathrm{Sm}(19.36 \mathrm{~nm})$, which shows that the $\mathrm{Ag}$ and $\mathrm{Sm}$ co-doped $\mathrm{TiO}_{2}$ catalyst can effectively inhibit the transformation from anatase to rutile phase, but also to some extent inhibit grain growth[13].

$\mathrm{TiO}_{2}$-Ag-Sm Photocatalytic Activity of the Catalyst. In order to examine the effects of microwave and ultrasonic on the photocatalytic activity, the best conditions for the preparation of $\mathrm{TiO}_{2}-\mathrm{Ag}-\mathrm{Sm}$ by microwave (MW), ultraviolet (UV), microwave and ultraviolet (MW-UV) and microwave ultraviolet-ultrasound (MW-UV-UT) of four kinds of degradation conditions are used for degradation of methyl orange solution. The result is shown in Fig. 4. As can be seen from Fig. 4, the degradation of methyl orange by $\mathrm{TiO}_{2}-\mathrm{Ag}-\mathrm{Sm}$ is not obvious under microwave irradiation alone. The degradation rate of methyl orange is only $11.87 \%$ when the degradation time is $25 \mathrm{~min}$. In UV, MW-UV and MW-UV-UT three kinds of degradation conditions, the effect of $\mathrm{TiO}_{2}$-Ag-Sm on the degradation of methyl orange are more obvious, when the treatment time is $25 \mathrm{~min}$, the degradation rate of methyl orange are $97.40 \%, 98.72 \%$ and $99.90 \%$; when the treatment time is 55min, almost complete degradation of methyl orange. This shows that microwave and ultrasound can enhance the photocatalytic degradation activity of $\mathrm{TiO}_{2}-\mathrm{Ag}-\mathrm{Sm}$. 
$\mathrm{TiO}_{2}$-Ag-Sm Catalyst XRD Analysis. The XRD pattern of $\mathrm{TiO}_{2}-\mathrm{Ag}$-Sm and pure $\mathrm{TiO}_{2}$ catalyst is shown in Fig. 5. As can be seen from Fig. 5, the characteristic peaks of anatase and the appearance of rutile pure $\mathrm{TiO}_{2}$ atlas, using RIR method to calculate two crystal quality percentage are $32.95 \%$ and $67.05 \%$, which indicates that after high temperature calcination of $\mathrm{TiO}_{2}$ is composed of anatase and rutile two phases; compared with pure $\mathrm{TiO}_{2}$, Rutile characteristic peak the catalyst of $\mathrm{TiO}_{2}-\mathrm{Ag}-\mathrm{Sm}$ do not appear, the average size of calculated by the Scherrer formula [14] of two kinds of $\mathrm{TiO}_{2}$ particles in the catalyst are $19.36 \mathrm{~nm}$ and $28.27 \mathrm{~nm}$, which indicates that doping can effectively inhibit the transformation of anatase phase and the grain growth of rutile, so as to effectively improve the photocatalytic activity of $\mathrm{TiO}_{2}$ catalyst.

Fig. 6 is a XRD diagram of the $\mathrm{TiO}_{2}-\mathrm{Ag}-\mathrm{Sm}$ catalyst prepared by calcining at different temperatures. We can see from Fig. 6, when the calcination temperature reaches $700{ }^{\circ} \mathrm{C}$ when the catalyst appears the characteristic diffraction peaks of rutile phase, as the temperature continues to rise, the rutile phase diffraction peak is more and more strong, the rutile phase content increasing; calculated by RIR method of two-phase formula can be, $\mathrm{TiO}_{2}-\mathrm{Ag}-\mathrm{Sm}$ at $700{ }^{\circ} \mathrm{C}$ : rutile $\mathrm{W}_{\mathrm{R}}=2.06 \%$, anatase in $\mathrm{W}_{\mathrm{A}}=97.94 \% ; 750{ }^{\circ} \mathrm{C}$ : rutile $\mathrm{W}_{\mathrm{R}}=19.35 \%$, anatase $\mathrm{W}_{\mathrm{A}}=80.65 \%$; when the catalyst in the main phase of anatase and rutile phase, its photocatalytic activity is higher, but the proportion of rutile will affect high catalytic activity, therefore the different catalysts in the presence of an optimum ratio of anatase and rutile phases.

SEM and EDS Analysis. The SEM image of $\mathrm{TiO}_{2}-\mathrm{Ag}-\mathrm{Sm}$ catalyst is shown in Fig. 7. It can be seen from Fig. 7 that the particle size distribution of the $\mathrm{TiO}_{2}-\mathrm{Ag}-\mathrm{Sm}$ catalyst is relatively uniform, which is favorable for photocatalytic degradation. At the same time, the specific micro-region of $\mathrm{TiO}_{2}-\mathrm{Ag}-\mathrm{Sm}$ is selected for full-spectrum scanning to determine the element types and their contents. The results are shown in Fig. 8 and Table 1.The results show that the main elements in $\mathrm{TiO}_{2}-\mathrm{Ag}-\mathrm{Sm}$ are $\mathrm{Ti}$ and $\mathrm{O}$, and contain trace $\mathrm{Ag}$ and $\mathrm{Sm}$ (Ag:0.02\%, Sm:0.09\%). This indicates that the $\mathrm{TiO}_{2}-\mathrm{Ag}-\mathrm{Sm}$ catalyst prepared by microwave hydrothermal synthesis is loaded with two elements Ag and Sm.
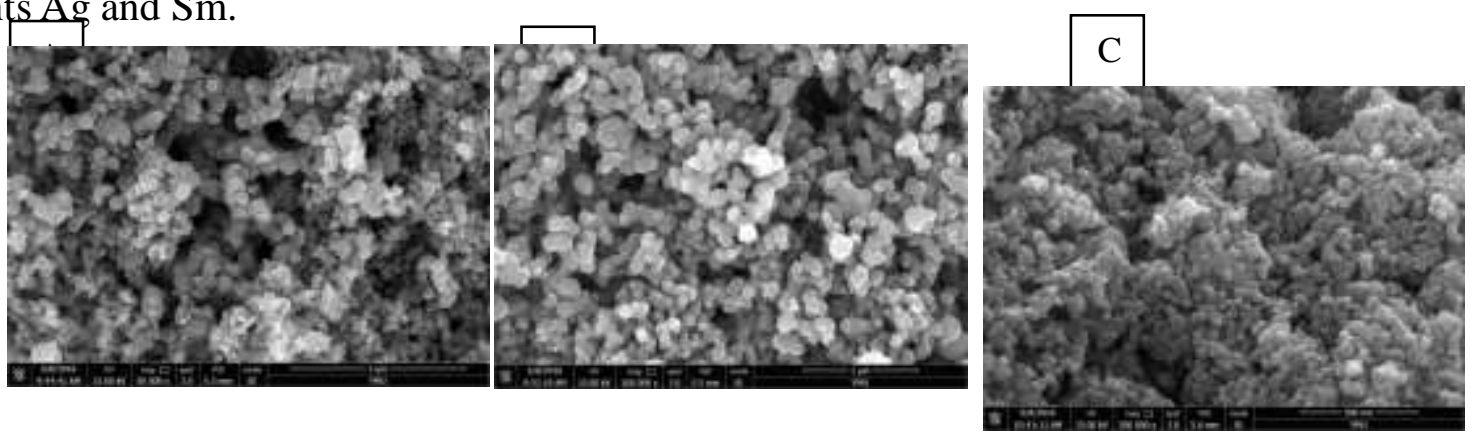

Figure 7. Finite SEM images of TiO2-Ag-Sm catalysts at different magnifications (A: 50,000 times; B: 100,000 times; C: 200,000 times)

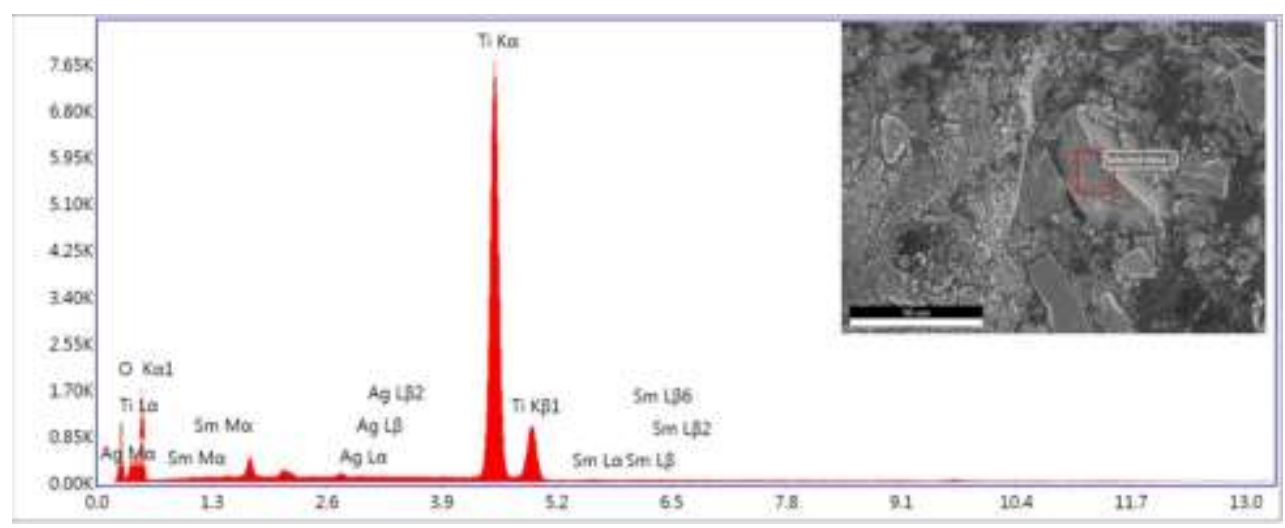

Figure 8. Finite $\mathrm{X}$-ray energy spectrum of $\mathrm{TiO}_{2}-\mathrm{Ag}-\mathrm{Sm}$ catalyst 
Table 1 EDS Elemental Analysis of $\mathrm{TiO}_{2}-\mathrm{Ag}-\mathrm{Sm}$ Catalyst

\begin{tabular}{lll}
\hline element & $W t \%$ & $A t \%$ \\
\hline OK & 41.64 & 68.27 \\
TiK & 57.74 & 31.62 \\
AgL & 0.08 & 0.02 \\
SmL & 0.54 & 0.09 \\
\hline
\end{tabular}

ICP-AES analysis. The contents of $\mathrm{Ag}$ and $\mathrm{Sm}$ in the $\mathrm{TiO}_{2}-\mathrm{Ag}-\mathrm{Sm}$ catalyst are quantitatively analyzed by ICP-AES to investigate the loading of the doping elements. The results are shown in Table 2. The theoretical doping amounts of $\mathrm{Ag}$ and $\mathrm{Sm}$ are $0.30 \%\left[\mathrm{n}\left(\mathrm{Ag}^{+}\right): \mathrm{n}\left(\mathrm{Ti}^{4+}\right)=0.3 \%\right.$ and $\mathrm{n}\left(\mathrm{Sm}^{3+}\right): \mathrm{n}\left(\mathrm{Ti}^{4+}\right)=0.3 \%$ in the preparation of $\mathrm{TiO}_{2}-\mathrm{Ag}-\mathrm{Sm}$, while the actual loadings of the two elements are $0.21 \%$ and $0.20 \%$, respectively, indicating that $\mathrm{TiO}_{2}$ and $\mathrm{Ag}$ are indeed loaded in the $\mathrm{TiO}_{2}$ catalyst during the preparation of $\mathrm{TiO}_{2}-\mathrm{Ag}-\mathrm{Sm}$ by microwave hydrothermal method.

Table 2. Results of ICP-AES analysis of $\mathrm{TiO}_{2}-\mathrm{Ag}-\mathrm{Sm}$ catalyst

\begin{tabular}{llccc}
\hline sample & $\begin{array}{l}\text { Doping } \\
\text { elements }\end{array}$ & $\begin{array}{c}\text { The actual doping } \\
\text { amount } / \%\end{array}$ & $\begin{array}{c}\text { Theoretical doping } \\
\text { amount } / \%\end{array}$ & $\begin{array}{c}\text { Load rate } \\
1 \%\end{array}$ \\
\hline \multirow{2}{*}{$\mathrm{TiO}_{2}-\mathrm{Ag}-\mathrm{Sm}$} & $\mathrm{Ag}$ & $0.21 \%$ & $0.30 \%$ & $70.0 \%$ \\
& $\mathrm{Sm}$ & $0.20 \%$ & $0.30 \%$ & $66.7 \%$ \\
\hline
\end{tabular}

UV-Vis Absorption Spectroscopy. Fig. 9 shows the UV-Vis spectra of pure $\mathrm{TiO}_{2}$ and $\mathrm{TiO}_{2}-\mathrm{Ag}-\mathrm{Sm}$ prepared by microwave hydrothermal method. It can see from Fig. 9, compared with the pure $\mathrm{TiO}_{2}, \mathrm{TiO}_{2}-\mathrm{Ag}-\mathrm{Sm}$ of UV and visible light is absorbed, and the light absorption edge red shifted from pure $\mathrm{TiO}_{2}(390 \mathrm{~nm})$ to $\mathrm{TiO}_{2}-\mathrm{Ag}-\mathrm{Sm}(443 \mathrm{~nm}) 53 \mathrm{~nm}$ red shift, which effectively will the optical absorption of $\mathrm{TiO}_{2}$ extended to the visible. Using the formula $\mathrm{Eg}=1240 \mathrm{eV}$ lambda can calculate the band gap of pure $\mathrm{TiO}_{2}$ and $\mathrm{TiO}_{2}-\mathrm{Ag}-\mathrm{Sm}$ are $3.02 \mathrm{eV}$ and $2.80 \mathrm{eV}$, which shows the relatively pure $\mathrm{TiO}_{2}$ doped $\mathrm{TiO}_{2}$ band gap width is reduced by $0.22 \mathrm{eV}$, which leads to the
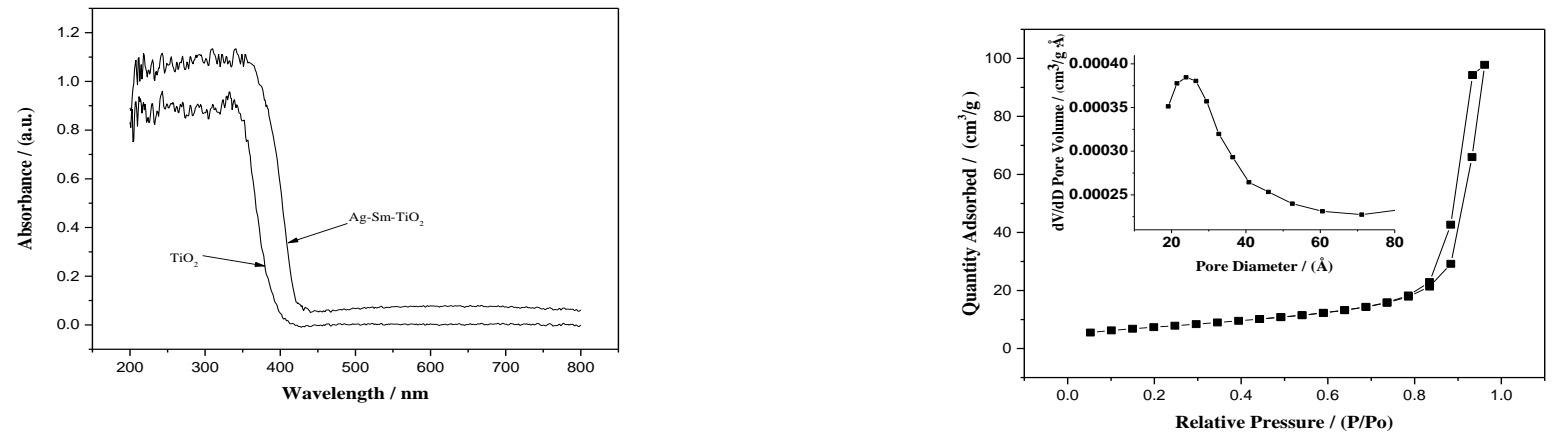

photoinduced electrons more easily across the gap, so as to improve the photocatalytic activity of $\mathrm{TiO}_{2}$-Ag-Sm catalyst.

Figure 9. Finite UV-Vis spectra of $\mathrm{TiO}_{2}$ and $\mathrm{TiO}_{2}-\mathrm{Ag}-\mathrm{Sm}$ catalyst

Figure 10. Finite $\mathrm{N}_{2}$ adsorption-desorption isotherms and pore size distribution of $\mathrm{TiO}_{2}-\mathrm{Ag}-\mathrm{Sm}$ catalyst

Table 3 Specific surface area, pore volume and pore size test results for $\mathrm{TiO}_{2}-\mathrm{Ag}-\mathrm{Sm}$ catalyst

\begin{tabular}{lllllll}
\hline Sample & $\begin{array}{l}\mathrm{S}_{\text {Langmuir }} \\
{\left[\mathrm{m}^{2} / \mathrm{g}\right]}\end{array}$ & $\begin{array}{l}\mathrm{S}_{\mathrm{BET}} \\
{\left[\mathrm{m}^{2} / \mathrm{g}\right]}\end{array}$ & $\begin{array}{l}\mathrm{V}_{\text {BJH-adsorpti }} \\
\text { on } \\
\left(\mathrm{cm}^{3} / \mathrm{g}\right)\end{array}$ & $\begin{array}{l}\mathrm{V}_{\text {BJH-desorpti }}\left[\mathrm{cm}^{3} / \mathrm{g}\right] \\
\text { on }\end{array}$ & $\begin{array}{l}\mathrm{D}_{\text {BJH-adsorpti }}[\mathrm{nm}] \\
\text { on }\end{array}$ & $\begin{array}{l}\mathrm{D}_{\text {BJH-desorptio }} \\
\mathrm{n}[\mathrm{nm}]\end{array}$ \\
\hline $\mathrm{TiO}_{2}$-Ag-S & 90.785 & $\begin{array}{l}26.381 \\
\mathrm{~m}\end{array}$ & 0.044500 & 0.065716 & 6.6060 & 8.9031 \\
\hline
\end{tabular}


$\mathbf{N}_{2}$ Adsorption-Desorption Analysis. Fig. 10 shows the $\mathrm{N}_{2}$ adsorption-desorption and pore size distribution of $\mathrm{TiO}_{2}-\mathrm{Ag}-\mathrm{Sm}$ prepared by microwave hydrothermal method. Table 3 shows the specific surface area, pore volume and pore size of $\mathrm{TiO}_{2}-\mathrm{Ag}-\mathrm{Sm}$. As can be seen from Fig. 10 and Table 3, the $\mathrm{TiO}_{2}-\mathrm{Ag}-\mathrm{Sm}$ catalyst is a spherical mesoporous material with relatively uniform pore size distribution and smaller size. The larger the specific surface area is, the larger the contact area between the catalyst and the organic pollutant is, and the probability of contacting the catalytically active sites increases at the same time, effectively increasing the photocatalytic activity of the catalyst.

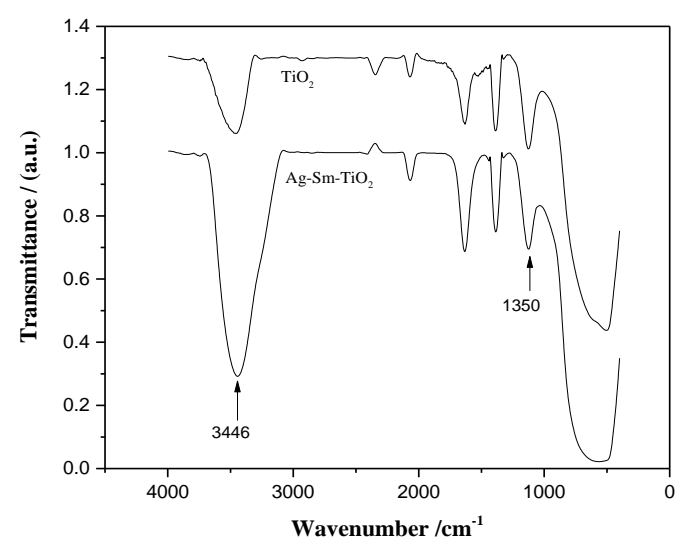

Figure 11. Finite Infrared spectra of $\mathrm{TiO}_{2}$ and $\mathrm{TiO}_{2}-\mathrm{Ag}-\mathrm{Sm}$ catalysts

Infrared Spectroscopy. Fig. 11 is an infrared spectrum of $\mathrm{TiO}_{2}$ and $\mathrm{TiO}_{2}-\mathrm{Ag}-\mathrm{Sm}$ catalysts. The figure $3446 \mathrm{~cm}^{-1}$ around the obvious hydroxyl stretching vibration peak, $1350 \mathrm{~cm}^{-1}$ is Ti-OH characteristic absorption peak. Comparing the two IR spectra in Fig. 11, it can be seen that the hydroxyl vibration peak of $\mathrm{TiO}_{2}-\mathrm{Ag}-\mathrm{Sm}$ is stronger than that of pure $\mathrm{TiO}_{2}$. Therefore, $\mathrm{Ag}$ and $\mathrm{Sm}$ doping contribute to the formation of more $\cdot \mathrm{OH}$ on the surface of $\mathrm{TiO}_{2}$ catalyst. It is advantageous to improve the catalytic activity.

\section{Conclusion}

The optimal conditions for the preparation of $\mathrm{TiO}_{2}-\mathrm{Ag}-\mathrm{Sm}$ catalyst by microwave hydrothermal method are optimized as follows: silver and samarium doped amount of $n\left(\mathrm{Ag}^{+}\right): \mathrm{n}\left(\mathrm{Ti}^{4+}\right)=0.3 \%$ and $\mathrm{n}\left(\mathrm{Sm}^{3+}\right):\left(\mathrm{Ti}^{4+}\right)=0.3 \%$, microwave power $600 \mathrm{~W}$, reaction temperature $150{ }^{\circ} \mathrm{C}$, reaction time $3 \mathrm{~h}$, calcination temperature $650{ }^{\circ} \mathrm{C}$ and calcination time $3 \mathrm{~h}$. The $\mathrm{TiO}_{2}-\mathrm{Ag}$-Sm catalyst prepared under these conditions degrades methyl orange almost completely when degrading methyl orange solution under UV, MW-UV and MW-UV-UT degradation for $55 \mathrm{~min}$.

The XRD patterns of $\mathrm{TiO}_{2}-\mathrm{Ag}-\mathrm{Sm}$ catalyst at different calcination temperature show that $\mathrm{Ag}$ and Sm doping can make the absorption of $\mathrm{TiO}_{2}$ extend to the visible region, when the relative mass fraction of the anatase phase and the rutile phase in the catalyst is optimal, this results in higher photocatalytic activity of the catalyst.

Characterization of the catalyst by XRD, SEM, EDS, ICP-AES, UV-Vis, $\mathrm{N}_{2}$ adsorption-desorption, X-ray energy dispersive spectroscopy and IR show that the $\mathrm{TiO}_{2}-\mathrm{Ag}-\mathrm{Sm}$ catalyst prepared by microwave hydrothermal method has the advantages of smaller particle size, surface area, pore volume and pore size larger, the surface of the number of high $\cdot \mathrm{OH}$, chemical stability and other advantages, resulting in its high photocatalytic activity.

\section{Acknowledgement}

C.M. Malengreaux, S.L. Pirard, and G. Léonard, et al:Journal of Alloys \& Compounds, Vol. 691 (2017), p.305. 


\section{References}

[1] Y.Z. Gou, D.P. He and Y.W. Liao, et al: Applied Chemistry, Vol. 40 (2011) No. 9, p.1559. (in Chinese)

[2] J. Thomas, S. Radhika and M. Yoon: Journal of Molecular Catalysis A Chemical, Vol. 411 (2016) No. 23, p.146.

[3] J. Schneider, M. Matsuoka and M. Takeuchi, et al: Chemical Reviews, Vol. 114 (2014) No. 19, p.9919.

[4] Y.J. Lu, X. Wang and X.J. Bi: Chinese Journal of Chemistry, Vol. 27 (2016) No. 6, p.748. (in Chinese)

[5] M.W. Li, M. Zhang and X.J. Bi, et al: Journal of Industrial Catalysis, Vol. 23 (2015) No. 12, p.986. (in Chinese)

[6] Y.J. Lu, M. Zhang and X.J. Bi: Journal of Industrial Catalysis, Vol. 25 (2017) No. 2, p.27. (in Chinese)

[7] G. Sodeifian, R, Behnood: Journal of Photochemistry \& Photobiology A Chemistry, Vol. 342 (2017), p.25.

[8] J. Anwar, U. Shafique and Waheed-uz-Zaman, et al: Arabian Journal of Chemistry, Vol. 8 (2015) No. 1, p.100.

[9] Z.Q. Chen, W.J. Zeng and W.K. Li, et al: Micrester of Management Science and Technology, (2010) No. 6, p.234. (in Chinese)

[10] L.Q. Wang, G.Q. Zhang and X.J Bi: Hans Journal of Chemical Engineering \& Technology, Vol. 4 (2014) No. 2, p.17.

[11] Y.J. Lu, X. Wang and X.J. Bi: Journal of Industrial Catalysis, Vol. 24 (2016) No. 11, p.19. (in Chinese)

[12] W. Raza, M.M. Haque, M. Muneer, et al: Journal of Alloys \& Compounds, Vol. 632 (2015), p.837.

[13] L. Elsellami, H. Lachheb and A. Houas: Materials Science in Semiconductor Processing, Vol. 36 (2015) No. 1-3, p.103. 